\title{
Investigating School Leadership within a European Project
}

\author{
Kathy Kikis-Papadakis
}

Institute of Applied and Computational Mathematics - Kriti (Greece)

doi: 10.7358/ecps-2015-011-kiki_katerina@iacm.forth.gr

\section{INDAGARE LA LEADERSHIP SCOLASTICA ALL'INTERNO DI UN PROGETTO EUROPEO}

\begin{abstract}
This article draws on the work conducted within the context of the European Policy Network on School Leadership. Its aim is to discuss and reflect upon school leadership policy development in the context of European education systems. The first section focuses on the concept of school leadership, identifying connections between school leadership practices and the promotion of equity and learning in schools. The second section discusses critical factors in policy implementation that shape the capacity of school leaders to combat inequalities and promote learning performance in schools. The article ends with an outlining of key policy actions for the promotion of distributed leadership practices in schools. In effect, this section stresses the need for a conceptual shift in understanding school leadership, from the position, roles, responsibilities, traits and capacities of the individuals holding formally assigned leadership roles in schools, to leadership as a function inside schools. As it is argued, such a conceptual shift calls for a policy shift in school leadership capacity-building that strengthens, but also goes beyond, the traditional repertoire of policies that focus on the preparation and professional training of school heads or other members of formal teams responsible for school management.
\end{abstract}

Keywords: Capacity-building, Equity, School leaders, School leadership, School policies. 


\section{INTRODUCTION}

This article draws on the work conducted within the context of the European Policy Network on School Leadership (EPNoSL) ${ }^{1}$. In particular, it is based on an in-depth review of school leadership policies in 21 European countries and the discourse that is taking place in EPNoSL's webinars, national workshops and peer learning activities organised in several European Union (EU) countries with the participation of a variety of school leadership stakeholders (including policymakers at European, national and local levels, school leaders, teachers and other professionals, academics, researchers, parents and students).

The EPNoSL project is based on the premise that school leadership plays a central role for the improvement and reform of teaching and learning, education policies and system development, as well as school management and administration. School leadership is also essential for creating an allinclusive education culture by overcoming individual and structural obstacles and inequalities. This view is widely shared within policy communities at the EU and national levels. The conclusions of the Education Council of November 2007, 2008 and 2009 identified, for instance, school leadership as a crucial factor for improving the quality of education and student/educational outcomes. School leadership figured prominently in the November 2009 Council conclusions on the professional development of teachers and school leaders (2009/C302/04), which stipulated that:

Effective school leadership is a major factor in shaping the overall teaching and learning environment, raising aspirations and providing support for pupils, parents and staff, and thus in fostering higher achievement levels. It is therefore of key importance to ensure that school leaders have, or are able to develop, the capacities and qualities needed to assume the increasing number of tasks with which they are confronted. Equally important is ensuring that school leaders are not overburdened with administrative tasks and concentrate on essential matters, such as the quality of learning, the curriculum, pedagogical issues and staff performance, motivation and development.

In spite of country differences among European education systems, ministers across Europe agreed to devote great care and attention "to defining the required profile of prospective school leaders, selecting them and preparing

1 The European Policy Network on School Leadership (EPNoSL) is a partner-run consortium created in 2011 in response to the increasing European focus on school leaders' professional development, including preparation and selection of school leaders. EPNoSL aims at improving policy and practice on school leadership in Europe. Find more information at: http://www.schoolleadership.eu/. 
them to fulfil their tasks» and to assure their competencies are continually updated. Addressing the challenges of studying, assessing and strengthening the role of school leadership for effective policy implementation, the EPNoSL project has stimulated discussion and reflection on the current trends of school leadership under the scope of facilitating policy articulation in the Network's Member States ${ }^{2}$.

This article attempts to reflect on school leadership policy development in the context of European education systems. The first section takes issue with the concept of school leadership. It attempts, specifically, to establish a connection between school leadership practices and the attainment of equity and learning in schools. This task is especially important, since the dominant literature on school leadership and equity tends to fail to acknowledge the structural constraints on social justice in neoliberal societies (Ward et al., 2014). As Ball (2012, p. 34) has argued, the construct of school leadership is often bound up with performativity and "governing by numbers", rather than equity. Against this trend, the article attempts to embed equity goals within the school leadership discourse. Its understanding of equity is not connected to the provision of the same educational experiences for all, or even about achieving the same outcomes for all groups irrespective of their characteristics (Lumby \& Coleman, 2007). Rather than equity meaning same treatment, it may be better understood as "giving all children an equal chance to be equipped to live a life they value» (Lumby, 2013, p. 19), which implies giving each child what is needed from their perspective, and this will not be the same in all cases.

The second section provides a brief analysis of a set of factors on policy implementation that are critical to shaping the capacity and potential of school leaders to effectively exercise school leadership in order to implement strategies and initiatives that are targeted to combat inequalities with regard to access, opportunities and learning outcomes, and to promote learning performance. The critical factors in policy implementation identified and discussed in this section are viewed from an «inner» and an «outer» perspective, although these two are not always easily distinguishable because of their interconnectedness. The outer perspective has to do with the ways each factor is assumed to play a critical role in policy implementation in a cluster of

2 See the EPNoSL policy briefs, Policy challenges on school leadership from the perspective of equity and learning at http://www.schoolleadership.eu/portal/deliverable/ policy-challenges-school-leadership-perspective-equity-and-learning and Promoting the policy agenda on school leadership from the perspective of equity and learning at http://www. schoolleadership.eu/portal/deliverable/promoting-policy-agenda-school-leadershipperspective-equity-and-learning. 
schools according to the organisation and management of schools in regions, education systems and whole countries. The inner perspective has to do with the ways each factor is assumed to play a critical role in policy implementation at individual school level.

The article ends with the attempt to put the reflections of the previous two sections into policy-related work. It thus outlines some key policy actions that are needed for the promotion of distributed leadership practices in schools. In effect, this section stresses the need for a conceptual shift in understanding school leadership, from the position, roles, responsibilities, traits and capacities of the individuals holding formally assigned leading roles in a school to leadership as a function inside schools. Such a conceptual shift consequently calls for a policy shift in school leadership capacity-building that strengthens, but also goes beyond, the traditional repertoire of policy strategies and initiatives that focus on the preparation and professional training of school heads or other members of formal teams responsible for the day-to-day management of schools.

\section{DEFINING SCHOOL LEADERSHIP}

EPNoSL has highlighted the importance of taking issue with the contested concept of «school leadership» in order to arrive at a tentative definition of the term that can act as the basis for further cohesive reflection on policy implications and recommendations. Through conducting analyses of country-specific academic and policy contexts, EPNoSL partners provided a European-wide reflection on how school leadership is perceived and acted upon in diverse educational, societal, and political contexts. In general, as it was originally expected, perceptions about the role of the school leader were found to vary among EU countries; school leadership was thus sketched by EPNoSL partners as a "concept with multiple meanings», strongly dependent on national cultures and contexts.

The synthesis of EPNoSL's country-specific analyses highlighted several of these national conceptual differences:

- In general, perceptions translate overlapping concepts to identify the position of the person responsible for the running of the school.

- They are called Principals, Head teachers, Directors, Managers, Leaders; these are titles for those who have authority over staff, the power of deciding over the many facets of the school organization, facilities, resources, curricular activity and. indirectly, over teaching and learning, over people, and the power of sharing decision-making and leadership. 
- In some statements, school leadership is referred to as a function (to lead, to manage, to represent, to encourage), a role (to represent, to be an interface, a colleague, a primus inter pares, to encourage, to motivate, to support) and as responsibilities, most of them related to policy, strategy and micro-politics.

- Multiple areas of school leaders' responsibility, such as the school mission, globally, and more specifically, school planning, teaching and learning, meeting goals and standards, evaluating and assessing performance of staff and students, caring for wellbeing and for the school image, leading on the level of what is legally defined.

On the basis of a mapping of these divergences, EPNoSL partners held online and offline discussions on how to arrive at a common understanding of school leadership that would concomitantly be valuable for further policy reflection and implementation at the European level, but without brushing aside the distinct dynamics that are essential for political interventions at national or local policy contexts. The approach proposed by EPNoSL, after these discussions took place, sees School Leadership (SL) as a multi-faceted process of strategically using the unique skills and knowledge of teachers, pupils and parents toward achieving common educational goals. Within the framework of educational goals, leadership is present at all levels of an organization, directed at serving the most important stakeholders, through inspiring others in the organization to take part in the management process. Likewise, management in leadership involves making the best use of the human, material and financial resources available.

School leadership is inextricably linked to reform and change, and promotes efficient education by taking into account the needs of each individual, institution, society and culture. As such, school leadership coveys dynamism and pro-activity and is not restricted to the activities of principals or school heads, but also includes other leaders in education, such as members of a formal leadership team and other actors who contribute towards the aims of the school, including student leadership.

School leadership for equity and learning. This article focuses on school leadership from the perspective of equity and learning. It thus builds upon the conceptual framework defined by the OECD report No more failures which suggests that equity in education can be understood through two closely intertwined dimensions: fairness and inclusion (Field, Kuczera, \& Pont, 2007). Fairness implies ensuring that personal and social circumstances, such as gender, socio-economic status, cultural background or ethnic origin, should not be an obstacle to students to achieve to the best of their educational potential. Inclusion implies ensuring a basic minimum standard of education for all. The perspective of learning in school leadership refers 
not only to students' experiences in the school, but also to learning experiences of the professionals involved in schooling. Since learning is not a visible process, it cannot be observed or measured. In this sense, learning is always about something we do not know (yet). Tests both on the micro level (classroom) and macro level (system, i.e., PISA) do not assess learning as such, but only its results (Schratz, 2013). Therefore, student achievement results only show how students respond to certain test items and do not mirror a student's capacity for learning. Learning is characterised by a high interconnectedness between cognitive, emotional and action processes and, as such, is a total human experience (Roth, 2001). In this regard, learning is also connected to the attainment of pupil well-being, which has been recognised as an important factor that appears relevant for the achievement of many educational aims (Ots, 2014).

School leadership from the perspective of equity. As Jacky Lumby and others have argued, typically in educational leadership and management discourse it is policymakers or family/society factors that are cited as maintaining inequality, and staff in schools depicted as constrained by the context within which they work (Begley \& Johansson, 2003; Lumby, 2013). However, this is a misleading assumption. Schools and school staff also play a part in creating, maintaining or increasing inequality. School leaders who attempt to shift school priorities and practices in fundamental ways usually encounter a modicum of support and a good deal of resistance from teachers and from parents. Teachers may argue, for example, that dismantling tracking jeopardises teaching their subject, or any other subject, well. School leaders who enrol students who are seen by others as "problematic" risk parents' reactions to avoid their school. Flight from schools with a high percentage of immigrant students has been noted in different countries. Above all, school leaders sometimes face a belief that some children are not educable or only educable with great difficulty. The children of immigrant families or of minority ethnic groups are more likely to be seen as having special needs than are other groups, reflecting deeply embedded prejudices that link being perceived as different with being less able. In short, school leaders face unjust discriminatory convictions that underpin many teachers and parents' judgements about what is right and possible in education. School leaders themselves are not immune from such beliefs or actions. Those who, for example, give entry preference to students with higher attainment, or who allocate the most inexperienced teachers to classes of those perceived as having lower ability, are enacting inequality (Lumby, 2012).

School leadership from the perspective of learning. There is little research that indicates a direct relationship between school leaders' behaviour and practices and students' learning achievement or to teachers' learning (see, 
for example, Coelli, \& Green, 2012). According to a much-cited review of the relevant literature by Leithwood et al. (2004) «mostly leaders contribute to student learning indirectly, through their influence on other people or features of their organizations». As they argue, "leaders' contributions to student learning, then, depend a great deal on their judicious choice of what parts of their organization to spend time and attention on" (ibid.). On their part, Branch, Hanushek and Rivkin (2009, p. 18) argue that «understanding the impact of principals on learning is a particularly difficult analytical problem. The non-random sorting of principals among schools and consequent difficulty separating the contributions of principals from the influences of peers and other school factors raise questions about the degree to which principals are responsible for differential outcomes». As they put it, "[...] it is often quite difficult to distinguish cause and effect, as those anointed as great leaders may simply have been in the right place at the right time» (Branch, Hanushek, \& Rivkin, 2012, p. 1). The difficulty in establishing a relationship between school leadership and student performance also surfaces in analyses of the PISA data. On the basis of the PISA 2009 dataset, a two-level regression model was tested where reading performance was regressed on all PISA learning environment and school climate (student and school level) composite indices. The results showed that before the socio-economic background of students and schools is taken into account, the performance of students is positively related to higher values on the index of leadership only in Spain among the EU countries. In contrast, it is negatively related in Slovakia, Finland and Italy (see OECD, 2010, Table IV.2.13b, p. 186). After accounting for the socio-economic background of students and schools, reading performance is (negatively) related to leadership only in Italy.

An analysis of the Teaching and Learning International Survey (TALIS) data (OECD, 2009) also shows lack of strong relationships between school leadership behaviour and teachers' practices (related to structuring, orientation to the student and enhanced activities), beliefs about instruction (direct transmission or constructivist) and attitudes (teacher's job satisfaction and self-efficacy) in the vast majority of the EU countries that participated in the survey. Only in Hungary, Lithuania, Poland and Portugal, among the $15 \mathrm{EU}$ education systems in TALIS (AT, BEFL, BG, DK, EE, HU, IE, IT, LT, MT, PL, PT, SK, SL, and ES), was the instructional leadership style positively related in a statistically significant way with increased teachers' co-ordination and professional collaboration in lower secondary education. Furthermore, only in Denmark, Hungary, Malta and Portugal are teachers more likely to report better relations with students if they work with a principal who adopts a more pronounced instructional style of leadership. These findings are con- 
sistent with studies such as those mentioned above that show the impact of school leadership to be indirect and moderated by teachers and other factors.

According to Leithwood, Harris and Hopkins (2008), although we lack evidence in sufficient amounts and of sufficient quality to serve as powerful guides to policy and practice on school leadership, there are some quite important things that we do know from previous school leadership research, which can provide the ground for a number of strong claims on school leadership:

- School leadership is second only to classroom teaching as an influence on pupil learning (leadership serves as a catalyst for unleashing the potential capacities that already exist in the organization).

- Almost all successful leaders draw on the same repertoire of basic leadership practices: (a) building vision and setting directions, (b) understanding and developing people, (c) redesigning the organization, and(d) managing the teaching and learning programme.

- The ways in which leaders apply these leadership practices - not the practices themselves - demonstrate responsiveness to, rather than dictation by, the contexts in which they work (apply contextually sensitive combinations of the basic leadership practices described above).

- School leaders improve teaching and learning indirectly and most powerfully through their influence on staff motivation, commitment and working conditions.

- School leadership has a greater influence on schools and pupils when it is widely distributed.

- Some patterns of distributed leadership are more effective than others (high levels of influence from all sources of leadership).

- A small handful of personal traits explain a high proportion of the variation in leadership effectiveness (such as open-mindedness, readiness to learn from others, flexibility, optimism, persistency).

\section{CRITICAL FACTORS IN SCHOOL LEADERSHIP POLICY IMPLEMENTATION}

Critical factors in school leadership policy implementation are the building blocks of a specific strategy or policy initiative that policy implementers can and even cannot control and manage in order to increase the chances of achieving the intended policy goals. Policy implementation is a complex and dynamic process in nature and, therefore, at different implementation phases it is likely that some factors may be proved more critical than others for its 
success. This article identifies the following factors that are likely to affect the realization of the three school leadership policy development goals:

- Political commitment and priorities.

- Financial resources.

- Policy coherence.

- Policy ownership.

- Empowerment of different stakeholders and trust in their professionalism.

- Supportive shared dispositions to inclusive, non socio-economically segregated schools.

Given the high diversity in the political, social, cultural and economic realities and traditions between and even within EU countries, some of the factors identified in this note may be less important than others in different countries or school education systems; it is also to be expected that the relative importance of different factors even in the context of a single country or education system may change with time or circumstances. Therefore, the scheme that is discussed here is neither exhaustive of the possible factors of some crucial importance to effective school leadership policy implementation nor rigid regarding its building blocks and their interrelationships.

\subsection{Political commitments and priorities}

Within the wider context of political debate over how to distribute limited public resources, it is important that governments clearly recognise the need to combat inequalities in access, opportunities and outcomes of schooling, and to prioritise measures that are aimed to address this problem. However, within the EU different national governments are facing diverse economic challenges and circumstances, and there is clearly the need to recognise that issues of equity in schools are likely to have become much more pressing in some of them after 2008. The austerity measures that have been introduced by several EU governments, notably in Greece, Italy, Spain, Portugal, Ireland and more recently Cyprus, as a response to the economic crisis, as well as the slow or even negative economic growth, have hit their education spending harshly. In these EU countries where cuts in education spending have been introduced there is a need to reformulate a wider consensus on the place of education in national policies and its role in the new economic environment. Such a consensus will also be helpful to orient school leadership policies and to establish priorities regarding equity and learning.

A new analysis of the PISA 2009 datasets undertaken in the context of EPNoSL shows that, in several EU countries, and most prominently in Malta, Bulgaria, Belgium, Austria, Germany, Luxemburg and Slovenia, there 
are wide gaps in average student performance in reading, mathematics and science between schools with a low, medium and high share of low SES students (Kollias, 2013). The above findings indicate that in these countries there is clearly the need to reaffirm policy commitment and devote more efforts aiming to reduce such gaps. Among other things, policy commitment and prioritisation of action targeting schools with a high intake of low SES students has to be accompanied by a heightened focus on the specific needs and challenges that school leaders face in such schools in order to better inform school leadership policies. International cooperation and knowledge and experience sharing is also important. On this front there is a lot to be learned from the cases of Finland and Poland, but also of Latvia and Denmark, which managed to achieve both comparatively high average overall performance and low variation in the average performance of students in schools with low, medium and high share of low SES students.

At school level, school leaders and teachers, although often sincerely convinced of their commitment to equality, and who consider themselves to be acting with fairness and inclusiveness, sometimes tend to prioritise other aims, such as maintaining their subject, the school's prestige, and their own daily professional survival. The causes of inequality are multiple and complex and not all under the control of educators, but school leaders have their own share in minimising or exacerbating the effects of economic inequality and exclusion within their schools. It is their determination to minimise these effects and the degree to which they prioritise this aim that is the foundation of action for equity and improved performance at school level (Lumby, 2013).

\subsection{Financial resources}

The level of spending, the sources of funding, the processes through which funding is becoming available to schools and the flexibility with which school leaders can use school funds to promote equity and learning are particularly important parameters for policy implementation. Across EU countries the level of public expenditures varies widely as a percentage of GDP and it is to be expected that in countries where public expenditures are comparatively low, less funds are becoming available to schools to promote programmes and interventions, such as extra classes for weaker pupils, greater variety of learning opportunities, meals to poorer pupils etc, that would scaffold school leaders and teachers' efforts to promote equity and learning.

In 2011 and/or 2012, cuts in education budgets were made in twenty countries/regions in the EU. Nine member states/regions (GR, IT, CY, LV, 
LT, HU, PT, RO, UK Wales) suffered budget cuts of more than 5\%, whereas decreases between 1 and $5 \%$ were reported in eleven countries/regions (BEFR, BG, CZ, IE, EE, ES, FR, PL, SK, SI, UKSC). These drastic reductions in education expenditure were made possible through teacher salary cuts or freezes that were implemented in most EU member states, with a few exceptions where teacher salaries increased in 2012 through reforms of the salary structure (CZ, PL, SK, RO, IS) (Eurydice, 2013b). Things are becoming worse in countries hit by the economic crisis, given that increased unemployment and cuts in salaries and pensions have reduced the capacity of many families to spend more on the education of their children and hence offer financial support to improve school services and infrastructure.

In this critical juncture, the challenge for policymakers is to ensure that persisting economic challenges do not become an overwhelming obstacle for the establishment of an enabling school leadership environment. In particular, policymakers need to address the following policy actions in order to overcome the pressing challenges brought by the economic crisis:

- It is essential to work towards more efficient, better targeted and more participative funding strategies for the promotion of equity and learning outcomes in schools.

- Financial support for developing capacity-building programs needs to be safeguarded.

- Financial support to the most disadvantaged students and schools needs to be reaffirmed through more flexible and responsive financial strategies that can be adaptive to the precarious conditions caused by the continuing economic crisis.

As the causes of inequalities in education become more complex and diverse, funding mechanisms should also adjust to the needs of disadvantaged students and schools that transcend immediate instructional concerns (e.g. earmarked support for students from families hit by the economic crisis, providing meals for poorer pupils and so on).

\subsection{Policy coherence}

Socio-economic and cultural factors that cannot be controlled directly by school leaders and teachers can gravely affect equity and learning in schools. From this perspective, it is of critical importance in EU countries where austerity measures have been introduced as a response to the recent economic crisis, to make efforts so as to ensure that these do not further deepen inequalities in income distribution, especially in communities and regions where there was already a high share of low income households. It should be 
stressed and become better understood by all stakeholders involved in policymaking and implementation that in order to promote equity and learning in schools there should be a deepening of sectorial coordination between education policies and other government policies that target to improve the socioeconomic situation of the most socio-economically disadvantaged regions and communities through, for example, welfare policies, employment policies, LLL policies etc.

At school level, policy coherence can be exemplified through coordinated leadership action involving the formulation of the school's mission, development plans and priorities, school spending, curricula, staffing, professional development, extra-curricular and out-of-school activities, networking, engagement in community projects etc. targeting specific school and community needs in relation to equity in access, opportunities, and outcomes and improved learning performance for all. At this level, given that the socio-economic and cultural background of students has been found to play a considerable role in student performance in many EU countries, leadership policy coherence, particularly in schools with a high share of low SES students, is greatly enhanced through the deepening of involvement of schools in the local community, serving its needs as community learning centres.

\subsection{Policy ownership}

Policy ownership can be conceptualised as a (perceived) state of belonging to, and responsibility for, the implementation of a strategy or initiative. A dispersed, rather than a top-down, model of implementation is more likely to ensure that various stakeholders (e.g. school leaders, parents, pupils and local authorities) view policy as benign, rather than an alien interloper (Bagley \& Ward, 2013). An initiative that is adopted willingly, even though it may have arisen externally, is much more likely to be successful than one that is imposed externally or internally on unwilling or unconvinced staff (Earley, 2013). The way that people perceive change will affect the way that they respond. Therefore, if they perceive that the change has been forced on them, they may well resist it, particularly if they feel it is counter to their interests. It follows from this that it is important to ensure that implementers at least understand what the change involves and that ideally they should feel some involvement with, and ownership of, the policy.

Policy ownership at school level can be greatly enhanced through distributed leadership and the widening of participation of school level stakeholders in decision-making and in the implementation of policies and projects aimed to promote equity and learning. 


\subsection{Empowerment of different stakeholders and trust in their professionalism}

Policy ownership is supported and enhanced by the sharing of power between different stakeholders. Policy empowerment and trust in different "key actors" shapes the degree and the nature of their involvement in the implementation of a policy or initiative. In school education systems where power is more widely shared and devolved it is likely that the implementation of strategies and initiatives targeting to promote school leadership for equity and learning will be handled more smoothly and successfully than in highly hierarchical systems.

At school level, school leaders must try to empower staff by making their own professional and educational values explicit and by sharing them. In this way, an agreed collegiate culture can be created, encouraging a learning environment for all staff and pupils. Commitment and collegiality in others has to be developed, and leaders need to involve staff in decision-making, allowing them to take ownership of their work, valuing them, and translating clear vision and purpose. Trust, empowerment and engagement are key components of collegiate cultures where change is not seen as a threat, but as part of everyday practice (Earley, 2013).

\subsection{Supportive shared dispositions to inclusive, non socio-economically segregated schools}

Beliefs about the capacity to learn and how far it relates to innate ability or to effort and beliefs about the impact of families on early learning are culturally shaped. School leaders who, for example, give entry preference to learners with higher attainment, or who allocate the most inexperienced teachers to classes of those perceived as having lower academic potentials are enacting inequality. Unpacking one's own culture and its assumptions about people and about learning may move school leaders out of their habitual thinking and behaviours, thereby raising awareness of how they are shaped by gender, ethnicity, class and societal culture (Lumby, 2013).

From a policy perspective the capacity of governments to devise policies that would promote schools with balanced student intake in terms of their socio-economic background is rather limited because of the complexity and the highly controversial nature of the issues involved. What they can do is to promote among the population the belief that all schools, irrespective of their intake and hence irrespective of the economic and social conditions in the place where schools are located, can promote equally well the well-being and learning performance of students. Such beliefs can be established through strategies 
and coordinated policy initiatives that aim to reduce inequalities in income distribution, to improve the standards of living in poorer neighbourhoods and regions, to enhance the quality and diversity of the services and infrastructure (schools included) available to the citizens living in these areas etc.

\section{PRomoting Distributed LEADERSHIP FOR EQUiTy AND LEARNING}

In recent years, distributed school leadership has been increasingly identified as a key policy strategy in order to improve the quality of education (OECD, 2008; ETUCE, 2012). The distribution of leadership tasks and responsibilities across different people and organisational structures is expected to strengthen school management, to make school administration more effective and to improve learning outcomes.

21st century schooling needs a shift away from vertical, policy-driven change to lateral, capacity-building change. School leaders must still have sufficient knowledge of facilities, personnel and finance management, but effective leaders today must also foster learning environments where students and professionals in the school are encouraged to share knowledge, build trust and promote a sense of shared responsibility.

As Ton Duif et al. (2013) have convincingly argued:

The need for distribution of leadership within the school is not only a pragmatic issue of proportionally dividing the school leaders workload, it has the positive impact on the self-efficacy of teachers and other staff members by encouraging them to show leadership based on their expertise and by supporting collaborative work cultures. This in turn is one of the most important conditions for a culture of improvement being at the heart of the school.

Although studies on the concrete impact of distributed leadership on education systems remain rather inconclusive (Harris, 2009), recent findings have shown that practices of distributed school leadership currently exist in many European countries, albeit in different forms (see, for example, Duif et al., 2013). Recent evidence shows that these forms fall under three broad categories: (a) cases where school leadership tasks are distributed between formal leadership teams (for example, in EL, CY, PT, ES, FR, IE, LU, HR, SI, SK, $\mathrm{CZ}$, and DK), (b) instances when informal ad-hoc groups assume specific and time-limited leadership tasks (for example, in DE), and (c) situations where local school autonomy is predominant, meaning that each school can decide about leadership distribution (for example, in NL, SE, FI and EE) (Eurydice, 2013a, pp. 117-118). 
Wide divergences and confusion about the meaning and implementation of distributed school leadership are indeed the norm in contemporary policy debates. The EPNoSL project has proposed a working definition of the term that policymakers can consult in order to address these conceptual problems. Distributed school leadership is considered as a culture that:

- views leadership as emerging from ongoing flows of interactions across the organisation and its hierarchy, not simply from the actions of the top school manager or a formal leadership team,

- values leadership contributions from across the school and its hierarchy, and

- recognises that this view of leadership can be deployed in order to improve organisational effectiveness,

accompanied by an institutional structure that:

- spreads leadership opportunities beyond formal senior roles to enable different sources of expertise and perspectives to influence the school's work, development and innovative changes,

- facilitates flexible, collaborative working relationships across traditional boundaries and hierarchies, and

- tends towards the creation of flatter hierarchies (Woods \& Woods, 2013).

Distributed leadership should not be treated as an end in itself because it cannot automatically lead to organizational improvement across the educational system. Addressing equity and learning challenges benefits from forms of distributed leadership that promote participation and the extension and deepening of democratic processes within and beyond the school environment. On this basis, policymakers need to consider the following policy actions:

- Deepening distributed leadership for attaining both equity and learning goals should become part of a wider policy strategy based on the notion that participative and democratic decision-making can be more effective in identifying and meeting the local needs of disadvantaged groups of students as well as empowering staff and students to become active in the everyday operation of their school.

- Mainstreaming distributed leadership: it should be integrated into all areas of school leadership policy. Emphasis should be given to harmonising existing and future capacity-building education and training programs with a culture of distributed school leadership.

Factors such as education and school culture, existing degrees of autonomy and forms of accountability, school size, are critical in designing the implementation of distributed leadership models. The precise forms of distributed leadership that may be conducive to an enabling school leadership environment for equity and learning can vary since they heavily depend on context. 
We conclude with five requirements which we suggest would be helpful for policymakers to reflect upon when aiming to develop school leadership (Woods \& Roberts, 2013):

- Advancing the quality of school leadership requires developing the leadership capabilities of everyone in the school - both those who are in designated leadership positions and those (such as many teachers, support staff and students) who are not.

- Developing the leadership capabilities of all requires the development of school cultures and structures that provide the social, professional and institutional support necessary to create environments that facilitate individual initiative and collaborative working and learning.

- Developing and sustaining such school cultures and structures requires longterm investment on the part of schools, governments and other agencies that support schools.

- Distributed leadership requires respect for both autonomy (individual views, professionalism, creativity and needs) and authority (school purpose, goals, values and structures), which means school members helping to shape schools' educational purpose, values, etc. as well as working within these.

- Helping distributed leadership to be fair and of benefit to the learning of all requires it to be guided by a broad concept of social justice that encourages schools to ask critical questions about involvement (participative justice), respect (cultural justice), learning (developmental justice) and resources (distributive justice).

\section{CONCLUSION}

This article has attempted to articulate some initial reflections that can pave the way towards shaping a comprehensive policy agenda on school leadership in Europe. First, it called for a wide conceptualization of school leadership policy and practice, which is based on the notion of the inherent connection of school leadership with the policy goals of promoting equity and learning in European education systems. Second, it briefly drew some basic recommendations on policies that can enable the distribution of leadership roles and responsibilities in European schools with the purpose of empowering all school stakeholders to engage in collaborative initiatives which aim to combat inequalities and to improve learning performances.

Finally, we should stress that EPNoSL's approach on school leadership for equity and learning is based on the assumption that there is no unique road to policy development. There are different ways for EU Member States 
to address each of the policy goals and related policy action lines to achieve an advanced level of school leadership policy development. For example, EU Member States with a more centralized school system, such as France and Greece, will possibly need to consider different policy solutions compared to Member States with highly decentralized school systems, such as Sweden, Finland and the Netherlands, or to Member States where there is more than one school system, such as the United Kingdom, Germany or Belgium. Furthermore, EU Member States which are strongly affected by the economic crisis and have implemented huge cuts in their public expenditures on school education will need to consider solutions that make more efficient use of less available financial resources as compared to EU Member States that have managed well during the crisis and have maintained or have even increased their public expenditure on school education.

\section{REFERENCES}

Bagley, C., \& Ward, S. (2013). Policy response: A critical engagement. In A. Kollias (Ed.), The critical factors in the discourse on SL from the perspective of equity and learning. EPNoSL Project.

Ball, S. J. (2012). Global education inc. Abingdon: Routledge.

Begley, P., \& Johansson, P. (Eds.). (2003). The ethical dimensions of school leadership. London: Kluwer Academic.

Branch, G. F., Hanushek, E. A., \& Rivkin, S. G. (2012). Estimating the effect of leaders on public sector productivity: The case of school principals. CALDER Working Paper, 66.

Coelli, M., \& Green, D. A. (2012). Leadership effects: School principals and student outcomes. Economics of Education Review, 31(1), 92-109.

Duif, T., Harrison, C., van Dartel, N., \& Sinyolo, D. (2013). Distributed leadership in practice: A descriptive analysis of distributed leadership in European schools. In L. Moos \& P. Hatzopoulos (Eds.), School leadership as a driving force for equity and learning. Comparative perspective. EPNoSL Project, Del. 4.1.

Earley, P (2013). Leading and managing change: Why is it so hard to do? In A. Kollias (Ed.), The critical factors in the discourse on $S L$ from the perspective of equity and learning. EPNoSL Project.

ETUCE - European Trade Union Committee for Education (2012). ETUCE policy paper on school leadership. Bruxelles: ETUCE. Retrieved (10/12/2013) from: http://etuce.homestead.com/Policies/ETUCE_Policy_Paper_School_ Leadership_EN.pdf. 
Eurydice (2007). School autonomy in Europe. Policies and measures. Eurydice thematic report. Luxembourg: Publications Office of the European Union. Retrieved (10/12/2013) from: http://eacea.ec.europa.eu/education/eurydice/ documents/thematic_reports/090EN.pdf.

Eurydice (2013a). Key data on teachers and school leaders in Europe. 2013 Edition. European Commission, Education and Training.

Eurydice (2013b). Funding of education in Europe 2000-2012: The impact of the economic crisis. Luxembourg: Publications Office of the European Union. Retrieved (10/12/2013) from: http://www.oecd.org/education/school/44374889.pdf.

Field S., Kuczera, M., \& Pont, B. (2007). No more failures: Ten steps to equity in education. Paris: OECD.

Hallinger, P., \& Heck, R. H. (2010). Collaborative leadership and school improvement: Understanding the impact on school capacity and student learning. School Leadership and Management, 30, 95-110.

Kollias, A. (Ed.). (2013). The critical factors in the discourse on SL from the perspective of equity and learning. EPNoSL Project.

Leithwood, K. A., Harris, A., \& Hopkins, D. (2008). Seven strong claims about successful school leadership. School Leadership and Management, 28(1), 27-42.

Leithwood, K. A., Louis, K. S., Anderson, S., \& Wahlstrom, K. (2004). Review of research: How leadership influences student learning. Toronto: University of Minnesota.

Lumby, J. (2012). Disengaged and disaffected young people: Surviving the system. British Educational Research Journal, 38(2), 261-279.

Lumby, J. (2013). Longstanding challenges, new contexts: Leadership for equality. International Studies in Educational Administration, 40(3), 17-38.

Lumby, J., \& Coleman, M. (2007). Leadership and diversity: Challenging theory and practice in education. London: Sage.

Marzano, R. J., Waters, T., \& McNulty, B. A. (2005). School leadership that works: From research to results. Alexandria, VA: Association for Supervision and Curriculum Development (ASCD).

Mulford, B., \& Silins, H. (2009). Successful school principalship in Tasmania. Launceston, Australia: University of Tasmania, Faculty of Education.

OECD (2008). Improving school leadership, Vol. 1: Policy and Practice; Vol. 2: Case studies on system leadership. Paris: OECD. Retrieved (10/12/2013) from: http://www.oecd.org/education/school/improvingschoolleadership-home. htm.

OECD (2010). PISA 2009 results: What makes a school successful? - Resources, policies and practices, Vol. 4. Retrieved (10/12/2013) from: http://dx.doi. org/10.1787/9789264091559-en. 
OECD (2012). Education at a glance 2012: OECD indicators. Paris: OECD. Retrieved (10/12/2013) from: http://dx.doi.org/10.1787/eag-2012-en.

Ots, A. (2014). Ópilaste heaolu resilientsus ja móistestruktuuri areng: erinevused kooliga rahulolu säilitamisel ebameeldivate koolikogemuste ja klassiópetaja kasvatusstiili taustal. Estonian Journal of Education, 2(1), 132-161.

Roth, G. (2001): Fühlen, Denken, Handeln. Wie das Gehirn unser Verhalten steuert. Frankfurt: Suhrkamp.

Schratz, M. (2013). Beyond the reach of leading: Exploring the realm of leadership and learning. EPNoSL keynote article. http://www.schoolleadership.eu/sites/ default/files/leadership-for-learning-2013.pdf.

Ward, S. C., Bagley, C., Lumby, J., Woods, P., Hamilton, T., \& Roberts, A. (2014). School leadership for equity: Lessons from the literature. International Journal of Inclusive Education, 18, 1-14.

Woods, P. A., \& Roberts, A. (2013). Distributed leadership and social justice: A case study investigation of distributed leadership and the extent to which it promotes social justice and democratic practices. In L. Moos \& P. Hatzopoulos (Eds.), School leadership as a driving force for equity and learning. Comparative perspective. EPNoSL Project, Del. 4.1.

Woods, P. A., \& Woods, G. J. (2013). Deepening distributed leadership: A democratic perspective on power, purpose and the concept of the self published. Vodenje v vzgoji in izobraževanju, 2, 17-40.

\section{Riassunto}

L'articolo trae origine dal lavoro svolto nel quadro della rete politica europea sulla scuola della leadership. Il suo scopo è quello di discutere e riflettere sulla leadership scolastica e sullo sviluppo delle politiche nel contesto dei sistemi di istruzione europei. La prima sezione del testo si concentra sul concetto di leadership scolastica, identificando le connessioni tra le pratiche di leadership scolastica e la promozione dell'equità e dell'apprendimento nelle scuole. La seconda sezione illustra i fattori critici nella attuazione delle politiche che modellano la capacità dei dirigenti scolastici nel combattere le disuguaglianze e promuovere l'apprendimento nelle scuole. L'articolo si conclude con una articolazione di azioni politiche fondamentali per la promozione e la diffusione delle pratiche di leadership nelle scuole. In effetti, questa sezione sottolinea la necessità di un cambiamento nell'approccio alla leadership educativa, che tenga conto della posizione, dei ruoli, delle responsabilità, dei tratti e delle capacità delle persone che ricoprono ruoli dirigenziali formalmente riconosciuti nelle scuole di leadership come funzionali all'interno delle istituzioni educative. Come emerge dalla discussione proposta, si ritiene opportuno un ri-orientamento concettuale 
per promuovere un cambiamento politico che rafforzi la leadership scolastica ma che vada anche oltre il repertorio tradizionale delle politiche che si concentrano sulla preparazione e sulla formazione professionale dei capi di Istituto o di altri membri del team ufficialmente responsabili della gestione della scuola.

Parole chiave: Dirigenti scolastici, Dirigenza scolastica, Equità, Politiche scolastiche, Sviluppo di capacità. 